\title{
Physical Exercise and Falling among Older Patients with Diabetes: A Narrative Review
}

\author{
Walid Kamal Abdelbasset, $\mathrm{PhD}^{1,2^{*}}$ \\ ${ }^{I}$ Department of Health and Rehabilitation Sciences, College of Applied Medical Sciences, \\ Prince Sattam bin Abdulaziz University, Al-Kharj, Saudi Arabia \\ ${ }^{2}$ Department of Physical Therapy, Kasr Al-Aini Hospital, Cairo University, Giza, Egypt
}

\begin{abstract}
Both diabetes mellitus (DM) and aging have an effect on gait behavior, balance, muscle performance, and other medical complications related to the development of diabetic neuropathy, hypoglycemia, hypotension, cognitive impairment, pain, disturbed proprioceptions, and polypharmacy. The main goal of the present review study was to identify risk variables for hypoglycemiainfluenced falling in DM older people, to suggest protective interventions to reduce the occurrence and to explore the effect of physical exercise on falling among elderly individuals with DM. In July 2021, these keywords were used to search Google Scholar, PubMed, Embase: falling in elderly, DM complications, insulin, hypoglycemia, and physical exercise. Because falls are so common during activities, it is critical to figure out what elements influence balance and walking activity. Multi-medications, cognitive dysfunction, dementia, urinary incontinence, depression status, and hypoglycemia are just some of the issues that can affect the elements of controlling balance directly during motion. Others, such as multi-medications, cognitive dysfunction, dementia, urinary incontinence, depression status, and hypoglycemia, can affect balance control indirectly by disrupting posture mobility. Exercise training has been shown to increase body performance and reduce joint discomfort, as well as improve psychological status and quality of life, muscular strength and balance, lower the chance of falling, and improve overall health in the aged and older adults.(International Journal of Biomedicine. 2021;11(4):473-479.)
\end{abstract}

Key Words: older adults $\bullet$ falling $\bullet$ diabetes mellitus $\bullet$ physical exercise

For citation: Abdelbasset WK. Physical Exercise and Falling among Older Patients with Diabetes: A Narrative Review. International Journal of Biomedicine. 2021;11(4):473-479. doi:10.21103/Article11(4)_RA3

$\mathrm{D}^{\mathrm{i}}$ iabetes mellitus (DM) is continuing to be an increasing international health burden. ${ }^{(1)}$ Furthermore, diabetes is becoming more prevalent among the elderly worldwide as a result of increased life expectancy and the disease's widespread prevalence. ${ }^{(2)}$ Diabetic older persons have unique treatment needs. Hypoglycemia is a potential complication that might arise as a result of diabetes treatment. . $^{(3,4)}$

DM affects more than $10 \%$ of the older population, compared to $6 \%$ of the overall adult population, and it affects as many as $25 \%$ of nursing home residents. ${ }^{(5)}$ The care of older individuals comes with its own set of difficulties. Hypoglycemia episodes are a common consequence of DM

*Corresponding author: Walid Kamal Abdelbasset, PhD. Department of Health and Rehabilitation Sciences, College of Applied Medical Sciences, Prince Sattam bin Abdulaziz University, Al-Kharj, Saudi Arabia.E-mail: walidkamal.wr@gmail.com treatment with oral and insulin medicines. ${ }^{(3)}$ Hypoglycemia's repercussions are perhaps even more severe in fragile elderly individuals than others. ${ }^{(4)}$

For example, falling in the elderly is perhaps the first sign of hypoglycemia, with terrible implications such as bone fractures, poor life quality, and death. Not as prevalent as the elevated falling rate in this population, osteoporosis is also common, owing to the presence of concomitant disorders such as $\mathrm{DM}$, which is linked to impaired bone healthiness. ${ }^{(6)}$ Moreover, a number of drugs have been linked to the development of osteoporosis in older DM individuals. ${ }^{(6)}$

Older individuals are prone to a variety of health issues, the most common of which is falling, which is the primary reason for mortality among adults over age 65 . A fall can cause different health difficulties, ranging from the immediate (trauma, fractures, and lacerations) to the long-term (muscle fatigue, weakness, and fear of falls). ${ }^{(7)}$ Falling has a harmful 
influence on older individuals' life quality since it impacts their activities and mobility, and increases their death rate. Falling is very common among aged and older DM persons, particularly type $2 \mathrm{DM}$ (T2DM), which is a major risk factor. In people over age 65 , the incidence rate is around 39\% each year, and it is more common among those with uncontrolled glycemia. ${ }^{(8)}$ Despite the fact that there are many disorders linked to falling in the elderly, a probable common risk factor is a loss of balance. ${ }^{(9)}$ Furthermore, numerous DM drugs have been linked to falls in the older population. ${ }^{(6)}$

The main goal of the present review study was to identify risk variables for hypoglycemia-influenced falling in DM older people, to suggest protective interventions to reduce the occurrence and to explore the effect of physical exercise on falling among elderly individuals with DM. In July 2021, these keywords were used to search Google Scholar, PubMed, Embase: falling in elderly, DM complications, insulin, hypoglycemia, and physical exercise.

Causes of falling among older patients with DM

The causes of falls in older people are multifaceted, and DM has been identified as one of the major risk factors in several studies. ${ }^{(10,11)}$ Diabetic neuropathy, neuromuscular problems, musculoskeletal dysfunctions, neuropathic pain, diabetic foot, cognitive dysfunction, vestibular disturbance, pain, and anti-DM medicines that produce hypoglycemia all contribute to a higher risk of falling in diabetic older individuals. Furthermore, DM increases the incidence of osteoporosis and fractures. ${ }^{(10-12)}$

Because of changes in the structure and architecture of bones, such as collagen quality and bone minerals, the strength and quality of bone in diabetic and non-diabetic individuals are lowered. ${ }^{(13,14)}$ The severity, duration, and complications of DM, as well as a lack of food control, are all linked to a higher risk of fractures. ${ }^{(13)}$ Furthermore, excessive use of DM medicines, particularly thiazolidinediones (TZD), may increase the risk of fracture due to a decrease in bone quality and mass. DM may increase the number of impairment episodes in older people, resulting in a higher risk of falling. ${ }^{(15)}$

Due to the rising prevalence of DM worldwide, the risk of fractures and falls in DM individuals may become a major public health concern in the future, particularly among diabetic older people, who are frailer and more prone to bone loss and osteoporosis. ${ }^{(16)}$

Recognizing the number of factors linked to falling in diabetic older people is a difficult and time-consuming task. Many products have been shown to be of minor benefit to older people who are at risk of falling due to the difficulties of including them in clinical assessments. Furthermore, the most predictable determinant of falling is past falling; the susceptibility of falling increases as a result of previous experiences. ${ }^{(17)}$ This predictor, on the other hand, does not detect persons who have not fallen but does recognize the danger characteristics associated with falling. In addition, this predictor provides a reduced direction to the reasons for previous falls. As the primary goal is to intervene before an event occurs, the value of falling history is restricted because it does not reflect the detection of elements that contribute to falling. Finally, the most effective way is to identify persons who are exposed to dangers prior to falling and intervene in a timely manner to reduce these risks.

Factors associated with falling among older patients with DM

Diabetic older people are more vulnerable to falling than non-diabetic older people. When aging is combined with $\mathrm{DM}$, the chance of falling is increased by 17 times. ${ }^{(18)}$ Furthermore, age and diabetic consequences, such as impaired sensibility(peripheral neuropathy, retinopathy, and diabetic foot), are substantial factors in an individual's risk of falling. (19) Age, BMI, insulin medicines, neuropathy, heart illnesses, osteoarthritis, decreased balance, and weakness of the lower limbs have all been shown to raise the associated factors of falling in DM older individuals. ${ }^{(20)}$

\section{Hypoglycemia}

One of the commonest causes of unintentional lesions among older people is falls, which account for about $90 \%$ of wrist and hip fractures. Head injuries account for between $24 \%$ and $60 \%$ of all injuries. ${ }^{(21)}$ Long-term DM problems, such as diabetic foot ulcers, retinopathy, and diabetic neuropathy, are recognized to induce falling in senior individuals. ${ }^{(21)}$ Falls in DM people have been linked to a variety of risk factors. Aging, insulin medications, peripheral neuropathy, disturbed balance, obesity, osteoarthritis, cardiac diseases, and impaired lower limb function are all factors to consider. ${ }^{(20)}$

Diabetic individuals over age 65 have been reported to have a higher chance of falling and becoming disabled. One of the most feared acute consequences of DM therapy, hypoglycemia, has been proven to increase the chance of falling. Cognitive ability disturbance, palpitations, shakiness, and trembling are all signs that can contribute to hypoglycemiarelated falls. ${ }^{(22,23)}$

Falling caused by hypoglycemia may result in fractures, head and soft tissue injuries, and disorientation, which can lead to recurrent falls. ${ }^{(24)}$ Other comorbidities, including osteoporosis, in older persons may result in fractured bones. Accidents resulting in hospital visits were retrospectively analyzed in a large USA database among T2DM individuals on medicines (excluding insulin). ${ }^{(22)}$

Retrospective and case-control studies have also revealed an increase in hypoglycemia-induced falling and bone fracture, notably in individuals on insulin therapy who had strict glycemic control, but not in those on oral anti-DM drugs. ${ }^{(25)}$ Hypoglycemia is related to a considerably greater accident risk leading to hospitalization in T2DM individuals using insulin, including incidents involving falling and driving. ${ }^{(24)}$

In older patients, hypoglycemia has a significant negative effect on life quality. ${ }^{(22)}$ Hypoglycemia is feared by individuals more than any other diabetic condition, according to clinical experience. ${ }^{(26)}$ Hypoglycemia is related to diminished results in the elderly, including an increase of falling and fracture risks, as well as hospital admission, frailty, in-hospital mortality, and durable cognitive dysfunction, including dementia disorder. ${ }^{(27)}$ It is also linked to altered electrophysiology, including a longer QT interval, which is a recognized cause of cardiac arhythmia and can cause older people to fall. ${ }^{(28)}$

Anti-diabetic medications

One of the associated factors for falling is the use of anti-diabetic medications. ${ }^{(18)}$ It has been shown that taking 
several prescription medications raises the falling risk in older individuals. It was discovered that DM individuals who took more than four drugs had a higher risk of falling. ${ }^{(29,30)}$ As the number of drugs used increased, so did the risk of falling. Insulin-dependent diabetics have a greater hazard of falling and hypoglycemia than those who take oral DM medications. ${ }^{(24)}$

The risk of hypoglycemia is higher in those taking sulphonylureas than in people taking other oral DM medicines. ${ }^{(31)}$ The use of oral insulin sensitizers, on the other hand, was not linked to falls. TZD and metformin, for example, have not been demonstrated to raise the risk of falling. ${ }^{(32)} \mathrm{TZD}$, on the other hand, has been linked to increased fracture risks in DM individuals due to decreased bone tissue growth and hastened loss of bone tissues. Individuals who took dipeptidyl peptidase-4 inhibitors or glucagon-like peptide-1 analogs had no risk of falling. ${ }^{(33)}$

Insulin and glycemic management induced falling

Insulin-treated DM individuals were more likely to fall throughout the events of hypoglycemia, according to R.Kennedy. It was also discovered that insulin-treated individuals were more likely to break a bone as a result of falling. ${ }^{(34)}$

When non-insulin-dependent individuals were compared with insulin-dependent patients, the accident rates in insulindependent individuals were considerably higher. Insulin-treated individuals had the following characteristics: predominance of women, the elderly, and persons who had spent more time in the hospital. The fractures were mostly found around the periphery of the body. When compared to males, females also had a greater possibility of getting bone fractures during falling. ${ }^{(35)}$ DM individuals were shown to have a substantially greater rate of repeated falls. The number of drugs used, increasing intensity of discomfort, impaired grip strength, physical exercise, and disturbed cognition were all issues that contributed to increased falling risks. The relevance of glycemic control has been debated as a risk factor for falling. ${ }^{(18)}$

Researchers have investigated factors associated with DM individuals' falling and found that those who were poorly controlled were more susceptible to falling ${ }^{(8)}$ Falling in older individuals with DM, whether they have hypoglycemia or not, is prevalent, accounting for up to $31 \%$ of all recorded occurrences each year. Hemoglobin A1c (HbA1c) levels had no effect on the risks of falling in individuals who did not use insulin therapy. Individuals with $\mathrm{HbA1c}$ of less than $6 \%$ and those on insulin, on the other hand, were shown to be at a higher risk of falling. The importance of controlling HbAlc levels in DM management cannot be overstated. Regulating $\mathrm{HbAlc}$ could aid in delaying the long-term consequences linked with DM, resulting in weight loss. ${ }^{(19)}$

\section{Diabetic microcirculation problems}

One of the associated reasons for falling is identified as peripheral neuropathy. In diabetics with peripheral neuropathy, postural instability has been proven to cause falls. ${ }^{(36,37)}$ Poor clearance of creatinine was established as an indirect, associated reason for falling. ${ }^{(38)}$ Also associated with falling in DM individuals are microcirculation problems, poor kidney performance, peripheral nerve dysfunction, and visual disturbance. ${ }^{(38)}$
It was also discovered that falling-induced bone fractures occurred in older women even when they did not have incontinence of urine. It was theorized that prompt detection and incontinence management may assist older persons to avoid falling. Urinary frequency in older people is commonly known to be difficult to manage, because they tend to hurry to bathrooms to avoid incontinence disorder, making them prone to falling. ${ }^{(39)}$

Neuropathy and sensory dysfunction

Falling in DM individuals is caused mostly by sensory dysfunction-related neuropathy. Diabetic neuropathy affects around half of all diabetics, impairing their quality of life and raising their mortality risk. ${ }^{(40)}$ Neuropathy affects many sections of the autonomic and somatic nervous systems, whether large or small nerve fibers, in DM individuals. Age, poor microcirculation, persistent hyperglycemia, and oxidative stress are all common risk factors for neuropathy. ${ }^{(41)}$

In $40 \%$ to $100 \%$ of diabetic individuals, distal symmetric polyneuropathy develops, resulting in peripheral motor and sensory dysfunctions. Diabetic polyneuropathy can affect balance and walking, increasing the risk of falling in people with DM..$^{(40,42)}$ Controlling balance is critical for improving mobility, preventing impairment, and regaining independence in the elderly. ${ }^{(37)}$

\section{Balance system dysfunction}

Because the balance system is complex, pinpointing the source of the problem can be challenging because the dysfunction could be produced by one or more motor systems, as well as sensory systems, such as somatosensory, vestibular, and visual. In order to give an appropriate diagnosis and treatment choices, it is necessary to analyze the motor and sensory systems that affect balance. Muscle strength and balance are primarily affected by neuropathy in the ankle and foot, where myelinated sensory and motor nerve fibers terminate. In DM individuals with sensory dysfunctions, impairment of brain functioning can cause significant changes in standing and gait characteristics, ${ }^{(43)}$ such as a decrease in gait speed, an increase in postural motion, and a longer step duration. Also, whether standing or walking on a rough surface, the effect of this impairment is magnified. ${ }^{(44)}$ Nonfixed carpets and rugs and a slight difference in step height can slow reaction time; dorsiflexors weaken, and the capacity to prevent falls is lost, ${ }^{(45)}$ increasing the risk of falling threefold. Cognitive dysfunction

Falling can be triggered by a variety of causes, including motor and sensory dysfunctions, as well as a disruption in cognitive function, which impairs functional performance and bodily stability. According to the American Geriatrics Society, over $60 \%$ of older persons with cognitive dysfunction are at risk of falling every year. ${ }^{(46)}$ Falling in older people is linked to brain changes (pre-frontal cortex) that disrupt the executive control network. ${ }^{(47)}$ When assessing gait performance in individuals with cognitive impairment, it was discovered that changes in stride time are frequently linked to executive dysfunctions. ${ }^{(48)}$

Cognitive impairment can alter a person's perceptions of environmental risks and induce instability, which can lead to a fear of falling and a reduction in everyday activities. ${ }^{(49)}$ Fear of falling lowers self-esteem, limits movement and aerobic 
capacity, and increases the risk of falling. Despite the fact that many older persons are aware of the benefits of physical activity for boosting health and reducing the risk of falls, a significant number of those who have a high fear of falling avoid physical activities even if they are free of ailments or medical concerns. As a result, fear of falling is regarded as a crucial predisposing factor when assessing the risk of falling. ${ }^{(50)}$

Physical exercise and falling among elderly with DM

Repeated and sustained action of large muscle groups is required for aerobic exercise. ${ }^{(51)}$ Aerobic energy-producing systems are generally used in activities like walking, cycling, running, and swimming. Elastic resistance therabands, weight devices, and free weights are all examples of resistance (strength) training. Joint range of motion is improved by flexibility exercises. ${ }^{(41)}$ Exercises that improve balance and avoid falls are beneficial to one's gait. Flexibility, balance, and resistance are all combined in physical activities such as yoga and tai chi. ${ }^{(52)}$

Aerobic exercise

Aerobic exercise improves oxidative enzymes, insulin sensitivity, mitochondrial density, blood vessel compliance and responsiveness, cardiac output, pulmonary functions, and immunological performance. ${ }^{(53-56)}$ In both types of DM, T1DM and T2DM, moderate to high levels of aerobic activity are linked to significantly decreased cardiovascular and overall mortality risks. ${ }^{(57)}$ Aerobic training improves cardiorespiratory fitness, insulin resistance, endothelial functions, and levels of lipids in T1DM individuals. ${ }^{(58)}$ Regular physical exercises lower insulin resistance, lipids, blood pressure, and HA1C in T2DM individuals. ${ }^{(53)}$ High-intensity interval exercise leads to rapid improvements in insulin sensitivity, oxidative capacity of skeletal muscles, and control of glycemia in T2DM individuals, ${ }^{(59,60)}$ and could be completed with no effects on blood glucose level. ${ }^{(61)}$

Resistance exercise

Impaired muscle strength and a rapid loss in muscular performance are also risk factors for DM. ${ }^{(62)}$ Improvement in insulin sensitivity, blood lipids, body composition, bone density, blood pressure, muscle strength and mass, physical and mental functions, and cardiovascular well-being are all strong healthy points of resistance exercise. ${ }^{(63)}$ It is uncertain how resistance exercise affects glucose control in T1DM individuals. ${ }^{(61)}$ Resistance exercise, on the other hand, can help people with T1DM reduce their risk of hypoglycemia caused by exercise. When aerobic and resistance exercises are combined in a single workout, resistance training is performed first, which results in less hypoglycemia than aerobic activity. ${ }^{(64)}$ Insulin resistance, blood glucose levels, blood pressure, muscle strength, lean mass, and fat mass are all improved with resistance exercise for T2DM individuals. ${ }^{(65)}$

\section{Balance and flexibility exercise}

Balance and flexibility training are likely to be beneficial for DM seniors. The production of advanced glycation end products, which accumulate throughout the aging process and are increased with increased blood glucose levels, is one of the most common causes of limited joint mobility. Stretching improves joint flexibility and range of motion but has little effect on blood sugar management. ${ }^{(6)}$ Even if you have peripheral neuropathy, balance training can help you avoid falling by improving your balance and stride. Mixed exercise therapies (balance and resistance exercises, tai chi sessions) have been shown to prevent falls by $229 \%$. Alternative exercise forms, such as tai chi and yoga, are less well-studied, though yoga has been shown to enhance the management of body composition, hyperglycemia, and blood lipids in T2DM individuals. While studies on balance and flexibility exercises are limited, tai chi exercise could enhance good balance, reduce diabetic neuropathy, and improve life quality in neuropathic DM individuals. ${ }^{(66,67)}$

A large clinical study compared a lifestyle modification to DM support and educational groups in T2DM elderly individuals. In the lifestyle modification group, a minor nutritional energy shortage and unsupervised exercise for a minimum of 175 min a week were the targets of the intervention, which aimed for a weight loss of at least $7 \%$. Both groups had a similar number of major cardiovascular events, presumably because the diabetic support and education group used more cardioprotective drugs. ${ }^{(68)}$

Lifestyle modification

The focused lifestyle modification showed higher satisfactory progress in weight loss, blood lipids, blood pressure, cardiorespiratory condition, and blood glucose level with less medical treatment, as well as decreasing sleep disturbance, knee pain, DM retinopathy, kidney dysfunction, sexual problems, depression, and urinary incontinence, and improving the preservation of bodily flexibility and quality of life. Pi-Sunyer discovered very significant evidence of increased health advantages from a strict change in lifestyle. ${ }^{(69)}$

A systematic review on T2DM individuals found that aerobic exercise reduced HA1C more (by 20.18\%) than resistance exercise, but heart disease risk biomarkers were not lowered. ${ }^{(70)}$ Furthermore, physical activity enhanced glycemic control in diabetics, especially when done for at least 150 minutes per week. In persons with T2DM, strength training (free weights or weightlifting) improved physical infrastructure by around $50 \%{ }^{(24)}$ and lowered HA1C by $0.57 \% .{ }^{(71)}$ Combination training was preferable to either training program when it comes to glucose control. ${ }^{(72)} \mathrm{T} 2 \mathrm{DM}$ older individuals should preferably engage in both resistance and aerobic exercises to achieve the best glycemic control and health results.

\section{Conclusion}

Both DM and aging have an effect on gait behavior, balance, muscle performance, and other medical complications related to the development of diabetic neuropathy, hypoglycemia, hypotension, cognitive impairment, pain, disturbed proprioceptions, and polypharmacy. Because falls are so common during activities, it is critical to figure out what elements influence balance and walking activity. Multi-medications, cognitive dysfunction, dementia, urinary incontinence, depression status, and hypoglycemia are just some of the issues that can affect the elements of controlling balance directly during motion. Others, such as multi-medications, cognitive dysfunction, dementia, urinary incontinence, depression status, and hypoglycemia, can affect balance control indirectly by disrupting posture mobility. 
Physiological concerns, such as muscle strength and balance control, can also be effectively addressed through a variety of exercise programs. Exercise training has been shown to increase body performance and reduce joint discomfort, as well as improve psychological status and quality of life, muscular strength and balance, lower the chance of falling, and improve overall health in the aged and older adults. ${ }^{(73,74)}$

Aerobic exercise should be paired with therapeutic nutrition, according to studies on frailty in the aged population. ${ }^{(75)}$ Despite the fact that many studies have shown that balance training can reduce the risk of falling in older people, ${ }^{(76)}$ only a few studies have shown that this sort of exercise can enhance balance and gait pattern and lower the risk of falling in DM individuals. In addition, balance exercise may enhance gait and posture. ${ }^{(52,77)}$

Furthermore, physical activity has been shown to increase reaction speed, sensory perceptions, muscular strength, and sensory responses in the distal extremities, sympathetic/parasympathetic balance, neuropathy symptoms, nerve function, and cutaneous innervations. ${ }^{(77,78)}$

\section{Acknowledgments}

This publication was supported by the Deanship of Scientific Research at Prince Sattam bin Abdulaziz University.

\section{Competing Interests} interests.

The authors declare that they have no competing

\section{References}

1. Shaw JE, Sicree RA, Zimmet PZ. Global estimates of the prevalence of diabetes for 2010 and 2030. Diabetes Res Clin Pract. 2010 Jan;87(1):4-14. doi: 10.1016/j. diabres.2009.10.007.

2. Rathmann W, Giani G. Global prevalence of diabetes: estimates for the year 2000 and projections for 2030. Diabetes Care. 2004 Oct;27(10):2568-9; author reply 2569. doi: 10.2337/diacare.27.10.2568.

3. Hope SV, Strain WD. Hypoglycemia in the elderly. Diabetic Hypoglycaemia 2013;6(1):3-10.

4. Dominguez LJ, Paolisso G, Barbagallo M. Glucose control in the older patient: from intensive, to effective and safe. Aging Clin Exp Res. 2010 Aug;22(4):274-80. doi: 10.1007/BF03337724.

5. Sinclair AJ, Gadsby R, Penfold S, Croxson SC, Bayer AJ. Prevalence of diabetes in care home residents. Diabetes Care. 2001 Jun;24(6):1066-8. doi: 10.2337/diacare.24.6.1066.

6. Bollerslev J, Harris ST, Leder BZ. Medicines and bone loss. J Clin Endocrinol Metab. 2013 Apr;98(4):33A-4A. doi: 10.1210/jcem.98.4.zeg33a.

7. Burns ER, Stevens JA, Lee R. The direct costs of fatal and non-fatal falls among older adults - United States. J Safety Res. 2016 Sep;58:99-103. doi: 10.1016/j.jsr.2016.05.001.

8. Tilling LM, Darawil $\mathrm{K}$, Britton $\mathrm{M}$. Falls as a complication of diabetes mellitus in older people. J Diabetes Complications. 2006 May-Jun;20(3):158-62. doi: 10.1016/j. jdiacomp.2005.06.004.

9. Frank JS, Patla AE. Balance and mobility challenges in older adults: implications for preserving community mobility. Am J Prev Med. 2003 Oct;25(3 Suppl 2):157-63. doi: 10.1016/ s0749-3797(03)00179-x.

10. Mayne D, Stout NR, Aspray TJ. Diabetes, falls and fractures. Age Ageing. 2010 Sep;39(5):522-5. doi: 10.1093/ ageing/afq081.

11. Crews RT, Yalla SV, Fleischer AE, Wu SC. A growing troubling triad: diabetes, aging, and falls. J Aging Res. 2013;2013:342650. doi: 10.1155/2013/342650.

12. Strotmeyer ES, Cauley JA, Schwartz AV, Nevitt MC, Resnick HE, Bauer DC, et al. Nontraumatic fracture risk with diabetes mellitus and impaired fasting glucose in older white and black adults: the health, aging, and body composition study. Arch Intern Med. 2005 Jul 25;165(14):1612-7. doi: 10.1001/ archinte.165.14.1612.

13. Carnevale V, Romagnoli E, D'Erasmo L, D'Erasmo E. Bone damage in type 2 diabetes mellitus. Nutr Metab Cardiovasc Dis. 2014 Nov;24(11):1151-7. doi: 10.1016/j. numecd.2014.06.013.

14. de Waard EA, van Geel TA, Savelberg HH, Koster A, Geusens PP, van den Bergh JP. Increased fracture risk in patients with type 2 diabetes mellitus: an overview of the underlying mechanisms and the usefulness of imaging modalities and fracture risk assessment tools. Maturitas. 2014 Nov;79(3):265-74. doi: 10.1016/j.maturitas.2014.08.003.

15. Formiga F, Ferrer A, Padrós G, Corbella X, Cos L, Sinclair AJ, Rodríguez-Mañas L. Diabetes mellitus as a risk factor for functional and cognitive decline in very old people: the Octabaix study. J Am Med Dir Assoc. 2014 Dec;15(12):924-8. doi: 10.1016/j.jamda.2014.07.019.

16. Formiga F, Rodríguez Mañas L. [Elderly patients with diabetes mellitus and frailty. Association always present?]. Rev Esp Geriatr Gerontol. 2014 Nov-Dec;49(6):253-4.. doi: 10.1016/j.regg.2014.06.006. [Article in Spanish].

17. Vinik AI, Vinik EJ, Colberg SR, Morrison S. Falls risk in older adults with type 2 diabetes. Clin Geriatr Med. 2015 Feb;31(1):89-99, viii. doi: 10.1016/j.cger.2014.09.002.

18. Pijpers E, Ferreira I, de Jongh RT, Deeg DJ, Lips P, Stehouwer CD, Nieuwenhuijzen Kruseman AC. Older individuals with diabetes have an increased risk of recurrent falls: analysis of potential mediating factors: the Longitudinal Ageing Study Amsterdam. Age Ageing. 2012 May;41(3):35865. doi: 10.1093/ageing/afr145.

19. Schwartz AV, Vittinghoff E, Sellmeyer DE, Feingold KR, de Rekeneire N, Strotmeyer ES, et al.; Health, Aging, and Body Composition Study. Diabetes-related complications, glycemic control, and falls in older adults. Diabetes Care. 2008 Mar;31(3):391-6. doi: 10.2337/dc07-1152.

20. Volpato S, Maraldi C, Fellin R. Type 2 diabetes and risk for functional decline and disability in older persons. Curr Diabetes Rev. 2010 May;6(3):134-43. doi: 10.2174/157339910791162961.

21. Robinovitch SN, Feldman F, Yang Y, Schonnop R, Leung PM, Sarraf T, Sims-Gould J, Loughin M. Video capture of the circumstances of falls in elderly people residing in long-term care: an observational study. Lancet. 2013 Jan 5;381(9860):4754. doi: 10.1016/S0140-6736(12)61263-X.

22. Johnston SS, Conner C, Aagren M, Ruiz K, Bouchard J. Association between hypoglycaemic events and fallrelated fractures in Medicare-covered patients with type 2 diabetes. Diabetes Obes Metab. 2012 Jul;14(7):634-43. doi: 10.1111/j.1463-1326.2012.01583.x.

23. Maurer MS, Burcham J, Cheng H. Diabetes mellitus is associated with an increased risk of falls in elderly residents of 
a long-term care facility. J Gerontol A Biol Sci Med Sci. 2005 Sep;60(9):1157-62. doi: 10.1093/gerona/60.9.1157.

24. Chu E, Meinel N. Severe hypoglycemia and complications in elderly people with diabetes, hypoglycemia in hospitalized patients, and hypoglycemia and fall-related fractures. Diabetic Hypoglycemia. 2012;5(2):24-28.

25. Akram K, Pedersen-Bjergaard U, Borch-Johnsen K, Thorsteinsson B. Frequency and risk factors of severe hypoglycemia in insulin-treated type 2 diabetes: a literature survey. J Diabetes Complications. 2006 Nov-Dec;20(6):402-8. doi: 10.1016/j.jdiacomp.2005.08.005.

26. Workgroup on Hypoglycemia, American Diabetes Association. Defining and reporting hypoglycemia in diabetes: a report from the American Diabetes Association Workgroup on Hypoglycemia. Diabetes Care. 2005 May;28(5):1245-9. doi: 10.2337/diacare.28.5.1245.

27. Briscoe VJ, Davis SN. Hypoglycemia in type 1 and type 2 diabetes: physiology, pathophysiology, and management. Clin Diabetes. 2006;24(3):115-121.

28. Turchin A, Matheny ME, Shubina M, Scanlon JV, Greenwood B, Pendergrass ML. Hypoglycemia and clinical outcomes in patients with diabetes hospitalized in the general ward. Diabetes Care. 2009 Jul;32(7):1153-7. doi: 10.2337/ dc08-2127.

29. Huang ES, Karter AJ, Danielson KK, Warton EM, Ahmed AT. The association between the number of prescription medications and incident falls in a multi-ethnic population of adult type-2 diabetes patients: the diabetes and aging study. J Gen Intern Med. 2010 Feb;25(2):141-6. doi: 10.1007/s11606009-1179-2.

30. Kool B, Ameratunga S, Robinson E. Association between prescription medications and falls at home among young and middle-aged adults. Inj Prev. 2012 Jun;18(3):200-3. doi: 10.1136/injuryprev-2011-040202.

31. Bramlage P, Gitt AK, Binz C, Krekler M, Deeg E, Tschöpe D. Oral antidiabetic treatment in type-2 diabetes in the elderly: balancing the need for glucose control and the risk of hypoglycemia. Cardiovasc Diabetol. 2012 Oct 6;11:122. doi: 10.1186/1475-2840-11-122.

32. Berlie HD, Garwood CL. Diabetes medications related to an increased risk of falls and fall-related morbidity in the elderly. Ann Pharmacother. 2010 Apr;44(4):712-7. doi: 10.1345/aph.1M551.

33. Lecka-Czernik B. Bone as a target of type 2 diabetes treatment. Curr Opin Investig Drugs. 2009 Oct;10(10):1085-90.

34. Kennedy RL, Henry J, Chapman AJ, Nayar R, Grant P, Morris AD. Accidents in patients with insulin-treated diabetes: increased risk of low-impact falls but not motor vehicle crashes--a prospective register-based study. J Trauma. 2002 Apr;52(4):660-6. doi: 10.1097/00005373-200204000-00008.

35. Wallace C, Reiber GE, LeMaster J, Smith DG, Sullivan $\mathrm{K}$, Hayes S, Vath C. Incidence of falls, risk factors for falls, and fall-related fractures in individuals with diabetes and a prior foot ulcer. Diabetes Care. 2002 Nov;25(11):1983-6. doi: 10.2337/diacare.25.11.1983.

36. DeMott TK, Richardson JK, Thies SB, Ashton-Miller JA. Falls and gait characteristics among older persons with peripheral neuropathy. Am J Phys Med Rehabil. 2007 Feb;86(2):125-32. doi: 10.1097/PHM.0b013e31802ee1d1.

37. Abdelbasset WK. Falls in elderly patients with stroke. International Journal of Biomedicine. 2020;10(4):330-333.

38. Schwartz AV, Hillier TA, Sellmeyer DE, Resnick HE, Gregg E, Ensrud KE, et al. Older women with diabetes have a higher risk of falls: a prospective study. Diabetes Care. 2002
Oct:25(10):1749-54. doi: 10.2337/diacare.25.10.1749.

39. Brown JS, Vittinghoff E, Wyman JF, Stone KL, Nevitt MC, Ensrud KE, Grady D. Urinary incontinence: does it increase risk for falls and fractures? Study of Osteoporotic Fractures Research Group. J Am Geriatr Soc. 2000 Jul;48(7):721-5. doi: 10.1111/j.1532-5415.2000.tb04744.x.

40. Witzke KA, Vinik AI. Diabetic neuropathy in older adults. Rev Endocr Metab Disord. 2005 May;6(2):117-27. doi: 10.1007/s11154-005-6724-7.

41. Herriott MT, Colberg SR, Parson HK, Nunnold T, Vinik AI. Effects of 8 weeks of flexibility and resistance training in older adults with type 2 diabetes. Diabetes Care. 2004 Dec;27(12):2988-9. doi: 10.2337/diacare.27.12.2988.

42. Abdelbasset WK, Alrawaili SM, Nambi G, Yassen E, Moawd SA, Ahmed AS. Therapeutic effects of proprioceptive exercise on functional capacity, anxiety, and depression in patients with diabetic neuropathy: a 2-month prospective study. Clin Rheumatol. 2020 Oct;39(10):3091-3097. doi: 10.1007/ s10067-020-05086-4.

43. Colberg SR, Parson HK, Nunnold T, Holton DR, Swain DP, Vinik AI. Change in cutaneous perfusion following 10 weeks of aerobic training in Type 2 diabetes. J Diabetes Complications. 2005 Sep-Oct;19(5):276-83. doi: 10.1016/j. jdiacomp.2005.02.006.

44. Richardson JK, Thies S, Ashton-Miller JA. An exploration of step time variability on smooth and irregular surfaces in older persons with neuropathy. Clin Biomech (Bristol, Avon). 2008 Mar;23(3):349-56. doi: 10.1016/j.clinbiomech.2007.10.004.

45. Strotmeyer ES, de Rekeneire N, Schwartz AV, Resnick HE, Goodpaster BH, Faulkner KA, Shorr RI, Vinik AI, Harris TB, Newman AB; Health ABC Study. Sensory and motor peripheral nerve function and lower-extremity quadriceps strength: the health, aging and body composition study. J Am Geriatr Soc. 2009 Nov;57(11):2004-10. doi: 10.1111/j.15325415.2009.02487.x.

46. Soriano TA, DeCherrie LV, Thomas DC. Falls in the community-dwelling older adult: a review for primary-care providers. Clin Interv Aging. 2007;2(4):545-54. doi: 10.2147/ cia.s1080.

47. Coppin AK, Shumway-Cook A, Saczynski JS, Patel KV, Ble A, Ferrucci L, Guralnik JM. Association of executive function and performance of dual-task physical tests among older adults: analyses from the InChianti study. Age Ageing. 2006 Nov;35(6):619-24. doi: 10.1093/ageing/afl107.

48. Hausdorff JM, Yogev G, Springer S, Simon ES, Giladi N. Walking is more like catching than tapping: gait in the elderly as a complex cognitive task. Exp Brain Res. 2005 Aug;164(4):5418. doi: 10.1007/s00221-005-2280-3.

49. Menz HB, Lord SR, Fitzpatrick RC. A structural equation model relating impaired sensorimotor function, fear of falling and gait patterns in older people. Gait Posture. 2007 Feb;25(2):243-9. doi: 10.1016/j.gaitpost.2006.04.005.

50. Boyd R, Stevens JA. Falls and fear of falling: burden, beliefs and behaviours. Age Ageing. 2009 Jul;38(4):423-8. doi: 10.1093/ageing/afp053.

51. Physical Activity Guidelines Advisory Committee. Physical Activity Guidelines Advisory Committee Report. Washington, DC, U.S. Department of Health and Human Services. 2008; 683.

52. Morrison S, Colberg SR, Mariano M, Parson HK, Vinik AI. Balance training reduces falls risk in older individuals with type 2 diabetes. Diabetes Care. 2010 Apr;33(4):748-50. doi: 10.2337/dc09-1699.

53. Abdelbasset WK, Elsayed SH, Nambi G, Alrawaili SM, 
Elnegamy TE, Khalil MA, et al. Effect of Moderate-Intensity Aerobic Exercise on Hepatic Fat Content and Visceral Lipids in Hepatic Patients with Diabesity: A Single-Blinded Randomised Controlled Trial. Evid Based Complement Alternat Med. 2020 Apr 11;2020:1923575. doi: 10.1155/2020/1923575.

54. Abdelbasset WK, Osailan A. Sleep quality and ventilatory efficiency in elderly heart failure patients: a pilot study on the short-term effect of 4-week low-intensity aerobic exercise. Kardiologiia. 2020 Jul 7;60(6):938. doi: 10.18087/ cardio.2020.6.n938.

55. Elsayed S, Kamal W, Fathy K. Impact of active cycle of breathing technique on functional capacity in patient with bronchiectasis. Int J Ther Rehabil Res. 2015;4(5):287-293. doi: 10.5455/ijtrr.000000105.

56. Abdelbasset WK. Stay Home: Role of Physical Exercise Training in Elderly Individuals' Ability to Face the COVID-19 Infection. J Immunol Res. 2020 Nov 28;2020:8375096. doi: $10.1155 / 2020 / 8375096$.

57. Sluik D, Buijsse B, Muckelbauer R, Kaaks R, Teucher B, Johnsen NF, et al.. Physical Activity and Mortality in Individuals With Diabetes Mellitus: A Prospective Study and Meta-analysis. Arch Intern Med. 2012 Sep 24;172(17):1285-95. doi: 10.1001/ archinternmed.2012.3130.

58. Chimen M, Kennedy A, Nirantharakumar K, Pang TT, Andrews R, Narendran P. What are the health benefits of physical activity in type 1 diabetes mellitus? A literature review. Diabetologia. 2012 Mar;55(3):542-51. doi: 10.1007/s00125011-2403-2.

59. Abdelbasset WK, Tantawy SA, Kamel DM, Alqahtani BA, Elnegamy TE, Soliman GS, Ibrahim AA. Effects of highintensity interval and moderate-intensity continuous aerobic exercise on diabetic obese patients with nonalcoholic fatty liver disease: A comparative randomized controlled trial. Medicine (Baltimore). 2020 Mar;99(10):e19471. doi: 10.1097/ MD.0000000000019471. Erratum in: Medicine (Baltimore). 2020 Sep 11;99(37):e22388.

60. Abdelbasset WK, Tantawy SA, Kamel DM, Alqahtani BA, Soliman GS. A randomized controlled trial on the effectiveness of 8-week high-intensity interval exercise on intrahepatic triglycerides, visceral lipids, and health-related quality of life in diabetic obese patients with nonalcoholic fatty liver disease. Medicine (Baltimore). 2019 Mar;98(12):e14918. doi: 10.1097/ MD.0000000000014918. Erratum in: Medicine (Baltimore). 2020 Sep 11;99(37):e22388.

61. Tonoli C, Heyman E, Roelands B, Buyse L, Cheung SS, Berthoin S, Meeusen R. Effects of different types of acute and chronic (training) exercise on glycaemic control in type 1 diabetes mellitus: a meta-analysis. Sports Med. 2012 Dec 1;42(12):1059-80. doi: 10.1007/BF03262312.

62. Anton SD, Karabetian C, Naugle K, Buford TW. Obesity and diabetes as accelerators of functional decline: can lifestyle interventions maintain functional status in high risk older adults? Exp Gerontol. 2013 Sep;48(9):888-97. doi: 10.1016/j. exger.2013.06.007.

63. Garber CE, Blissmer B, Deschenes MR, Franklin BA, Lamonte MJ, Lee IM, et al.; American College of Sports Medicine. American College of Sports Medicine position stand. Quantity and quality of exercise for developing and maintaining cardiorespiratory, musculoskeletal, and neuromotor fitness in apparently healthy adults: guidance for prescribing exercise. Med Sci Sports Exerc. 2011 Jul;43(7):1334-59. doi: 10.1249/ MSS.0b013e318213fefb.

64. Yardley JE, Kenny GP, Perkins BA, Riddell MC, Malcolm J, Boulay P, Khandwala F, Sigal RJ. Effects of performing resistance exercise before versus after aerobic exercise on glycemia in type 1 diabetes. Diabetes Care. 2012 Apr;35(4):66975. doi: 10.2337/dc11-1844.

65. Abate M, Schiavone C, Pelotti P, Salini V. Limited joint mobility in diabetes and ageing: recent advances in pathogenesis and therapy. Int J Immunopathol Pharmacol. 2010 Oct-Dec;23(4):997-1003. doi: 10.1177/039463201002300404. 66. Ahn S, Song R. Effects of Tai Chi Exercise on glucose control, neuropathy scores, balance, and quality of life in patients with type 2 diabetes and neuropathy. J Altern Complement Med. 2012 Dec;18(12):1172-8. doi: 10.1089/acm.2011.0690.

67. Innes KE, Selfe TK. Yoga for Adults with Type 2 Diabetes: A Systematic Review of Controlled Trials. J Diabetes Res. 2016;2016:6979370. doi: 10.1155/2016/6979370.

68. Look AHEAD Research Group; Wing RR, Bolin P, Brancati FL, Bray GA, Clark JM, Coday M, et al. Cardiovascular effects of intensive lifestyle intervention in type 2 diabetes. N Engl J Med. 2013 Jul 11;369(2):145-54. doi: 10.1056/NEJMoa1212914.

69. Pi-Sunyer X. The Look AHEAD Trial: A Review and Discussion Of Its Outcomes. Curr Nutr Rep. 2014 Dec;3(4):387391. doi: 10.1007/s13668-014-0099-x.

70. Yang Z, Scott CA, Mao C, Tang J, Farmer AJ. Resistance exercise versus aerobic exercise for type 2 diabetes: a systematic review and meta-analysis. Sports Med. 2014 Apr;44(4):487-99. doi: 10.1007/s40279-013-0128-8.

71. Umpierre D, Ribeiro PA, Kramer CK, Leitão CB, Zucatti AT, Azevedo MJ, et al. Physical activity advice only or structured exercise training and association with HbA1c levels in type 2 diabetes: a systematic review and meta-analysis. JAMA. 2011 May 4;305(17):1790-9. doi: 10.1001/jama.2011.576.

72. Sigal RJ, Kenny GP, Boulé NG, Wells GA, Prud'homme D, Fortier M, et al. Effects of aerobic training, resistance training, or both on glycemic control in type 2 diabetes: a randomized trial. Ann Intern Med. 2007 Sep 18;147(6):357-69. doi: 10.7326/0003-4819-147-6-200709180-00005.

73. Abdelbasset WK, Alsubaie SF, Tantawy SA, Elyazed TIA, Elshehawy AA. A cross-sectional study on the correlation between physical activity levels and health-related quality of life in community-dwelling middle-aged and older adults. Medicine (Baltimore). 2019 Mar;98(11):e14895. doi: 10.1097/ MD.0000000000014895.

74. Abdelbasset WK, Nambi G. Relationship between physical activity and health-related quality of life in elderly people: a cross-sectional study. Sanamed. 2017;12:87-92.

75. Liao CD, Lee PH, Hsiao DJ, Huang SW, Tsauo JY, Chen HC, Liou TH. Effects of Protein Supplementation Combined with Exercise Intervention on Frailty Indices, Body Composition, and Physical Function in Frail Older Adults. Nutrients. 2018 Dec 4;10(12):1916. doi: 10.3390/nu10121916.

76. Peterson MJ, Giuliani C, Morey MC, Pieper CF, Evenson KR, Mercer V, et al. Health, Aging and Body Composition Study Research Group. Physical activity as a preventative factor for frailty: the health, aging, and body composition study. J Gerontol A Biol Sci Med Sci. 2009 Jan;64(1):61-8. doi: 10.1093/gerona/gln001.

77. Colberg SR. Physical activity, insulin action, and diabetes prevention and control. Curr Diabetes Rev. 2007 Aug;3(3):17684. doi: 10.2174/157339907781368986.

78. Kluding PM, Pasnoor M, Singh R, Jernigan S, Farmer K, Rucker J, Sharma NK, Wright DE. The effect of exercise on neuropathic symptoms, nerve function, and cutaneous innervation in people with diabetic peripheral neuropathy. J Diabetes Complications. 2012 Sep-Oct;26(5):424-9. doi: 10.1016/j.jdiacomp.2012.05.007. 